\title{
Factors affecting the bond strength between new and old concrete
}

\author{
Osama Mohamed ${ }^{(1)}$, Salah Gamal ${ }^{(2)}$ and Ashraf Amin ${ }^{(3)}$ \\ Civil Engineering dep. Faculty of Engineering, Minia University, Minia, Egypt ${ }^{(1)}$, \\ (usama_mm@mu.edu.eg) \\ Civil Engineering dep. Faculty of Engineering, Minia University, Minia, Egypt ${ }^{(2)}$
}

Civil Engineering dep. Faculty of Engineering, Minia University, Minia, Egypt ${ }^{(3)}$,

(Ashraf.abdelhamid@mu.edu.eg / +201117416818)

\begin{abstract}
One of the main concerns in repair is a sufficient bond between the substrate and the repaired material, especially for the long-term performance and durability of the structure. We carried out in this study an experimental work to investigate the effect of main parameters that primarily influence the bond between old and new concrete in dry, hot weather. The compressive strength considered for the case of old concrete is $15 \mathrm{MPa}$. While for the case of the new concrete, the considering compressive strengths as $15,30,40$, and $50 \mathrm{MPa}$. We cast a total of 48 cube samples $(10 \times 10 \times 10 \mathrm{~cm})$ and tested them for the grade of old concrete, the new concrete as a jacket in both faces of the old one. We prepared the substrate surface by grinding. We cast the new concrete over the old concrete where four cases of the bond between old and new concrete considered included using bond agent, using dowels, using bond agent and dowels, and without using bond agents or dowels. The samples were saved in the oven at $50^{\circ} \mathrm{C}$ for 28 days till the test day. Test results indicated that using new concrete with higher compressive strength slightly affected the bond between old and new concrete. While using a bond agent or dowels remarkably influenced the bond between old and new concrete and gave the same results, but using both gave maximum shear strength than other considered cases.
\end{abstract}

Keywords: Bond Strength, Shear Strength, roughness, nails. 


\section{Introduction}

Most structures have reached the end of their time life or were constructed wrong without achieving the design requirements (Ramasamy et al., 2021), so repairing these buildings is essential for using these structures. Many invented repair methods are for the rehabilitation of concrete members through adding a new concrete layer to the existing concrete members.

The cohesion, the friction properties of the concrete, and the stresses act on it played a paramount role in the capacity of the interface region between the substrate and the overlay layer (Al-Fasih et al., 2021). Many factors have effects on the cohesion and friction of the interface as surface preparation and curing methods. That increases the shear strength of the interface (Abd Malek et al. 2018),(Naresh, Lavanya, and Kumar 2021) stated that the more roughness for the substrate surface you will get more bond strength at the interface (Naresh, Lavanya, and Kumar 2021). Using shear connectors for increasing the bond strength of the interface is a paramount approach. Nguyen proved that using dowels enhances the flexural strength for the interface zone, and using $0.48 \%$ for dowels

Received: 12 July, 2021, Accepted:29 July , 2021 is considered a suitable choice (Nguyen, Serhatoğlu, and LiVaoĞLu 2018). It is a common way used in sites for strengthening the damaged concrete. BO LI used a direct shear test to study the shear strength between the ordinary concrete and the Ferro cement. Stated that the surface preparation technique more significant than using shear connectors ( $\mathrm{Li}$ and Lam 2018). Haber studied the consolidation of the new overlay and the substrate and stated that when good achieving consolidation, the roughness becomes less critical. While if not guaranteed, we should pay more attention to substrate roughness (Haber et al., 2018). Lopez showed that substrate roughness importance depends on the type of test for the interface on direct tensile strength. Test roughness has no role in the bonding strength because it depends on the chemical bonding agent used, push-off test, and slant shear test (López-Carreño et al., 2017). So we should know the stresses composed to the interface to face it with the suitable method (Bassam A. Tayeh) proved that the strength of the new concrete has a considerable effect on the bond strength more than the roughness in the tension tests (AL Hallaq, Tayeh, and Shihada 2017), Rith investigate the weak factors that may cause more stress on the overlay because of poor 
bonding at the interface and its results lead to that the substrate concrete conditions may cause poor bond which lead to, early stress on the overlay (Rith et al. 2016), generating shear frictions using steel dowels and improving the bond strength using different substrate roughness approaches, Elbakry performed a direct shear tests for new concrete jackets and stated that the samples with steel dowels have a greater shear strength about 4.6 than the samples without dowels and he found that using an epoxy resin did not give a remarkable difference in the shear strength at the interface and the adhesion of the epoxy resin to the old concrete is greater than the adhesion of the epoxy resin and the new concrete (Elbakry and Tarabia 2016).

The scope of our research is to investigate the influence of shear connectors and the epoxy resin and the differential stiffness of the new concrete, and the combination between them on the bonding strength at the interface, especially when curing the samples in bad conditions as dry, hot weather.

\section{Experimental programs}

\subsection{Used materials}

We used a coarse aggregate with a maximum nominal size of $15 \mathrm{~mm}$ for casting the new and old concrete grades, coarse-medium sand for fine aggregate, ordinary Portland cement (with cast grade of $42.5 \mathrm{~N} / \mathrm{mm}^{2}$ ), and silica fume casting the high compressive strength grades 40, 50 MPa. Table (1) shows the mixture proportions for each cast grade.
Table 1 Mixture proportions

\subsection{Specimens preparation}

Table $2 \mathrm{M}$

\begin{tabular}{|c|c|c|c|c|}
\hline \multirow{2}{*}{ Mix componentsKg/m } & \multicolumn{4}{|c|}{ Concrete grade MPa } \\
\cline { 2 - 5 } & $\mathbf{1 5}$ & $\mathbf{3 0}$ & $\mathbf{4 0}$ & $\mathbf{5 0}$ \\
\hline Gravel & 1400 & 1248 & 1173 & 1150 \\
\hline Sand & 760 & 672 & 628 & 626 \\
\hline Cement & 250 & 450 & 470 & 500 \\
\hline W/C & 0.75 & 0.4 & 0.37 & 0.33 \\
\hline Silica & 0 & 0 & 82 & 99.9 \\
\hline super plasticizer & 0 & 6.4 & 8.2 & 9.2 \\
\hline
\end{tabular}


An ordinary cubic concrete specimen $10 * 10 * 10 \mathrm{~cm}$ with $15 \mathrm{MPa}$ cast grade represented the old concrete repaired. Four weeks later, we demoulded the specimens, and we roughened old concrete specimen's substrate surface by grinding to achieve the same roughness. Because it is a fixed variable in this research (Fig. 1), samples with dowels prepared with a $6 \mathrm{~mm}$ diameter steel bars with $240 \mathrm{MPa}$ grade had an embedded length of $3 \mathrm{~cm}$ in the old concrete cubes from two sides using an epoxy agent specific for it (master flow 936 AN) (Fig. 2). The epoxy used for the interface (Master Brace ADH 1414) is a permanent epoxy adhesive for internal or external bonding of renderings, granolithic toppings, and concrete to concrete. It tolerates a degree of moisture before and during curing and is insoluble when cured. The ultimate bond strength is greater than the tensile strength of concrete. Master Brace ADH 1414 does not shrink and provides an even and stressfree bond, and its properties as shown in Table (2).

\begin{tabular}{|c|c|}
\hline $\begin{array}{c}\text { Mixed density ASTM D1475 @ } \\
25^{\circ} \mathrm{C}\end{array}$ & $1485 \mathrm{~kg} / \mathrm{m}^{3}$ \\
\hline Open time ASTM D2471 & $\begin{array}{c}25^{\circ} \mathrm{C} 150 \min 40^{\circ} \mathrm{C} \\
75 \min \end{array}$ \\
\hline Full cure ASTM C661 & 7 days \\
\hline $\begin{array}{l}\text { Slant shearbond strengthASTM } \\
\text { C882-99 }\end{array}$ & $>20 \mathrm{MPa}$ \\
\hline Water absorption ASTM D570 & $<0.1 \%$ \\
\hline $\begin{array}{c}\text { Compressive strength ASTMD695- } \\
91\end{array}$ & $>50 \mathrm{MPa}$ \\
\hline
\end{tabular}

We prepared samples with an epoxy resin also as shown in (Fig. 3) and cast concrete jackets on two opposite sides of the old cubes. After 4 weeks from casting the old concrete with variable strengths $15,30,40$, $50 \mathrm{MPa}$, the casting has been done for each strength without using nails, bonding epoxy with nails only, and nails and bonding epoxy. Test specimens for each new concrete grade as shown in (Fig. 4) (Elbakry and Tarabia 2016) with a total length of 24 $\mathrm{cm}$ and width of $10 \mathrm{~cm}$. We cast 12 samples and lifted them for four weeks in 500C in a dry oven to achieve the hot, dry weather which we study.
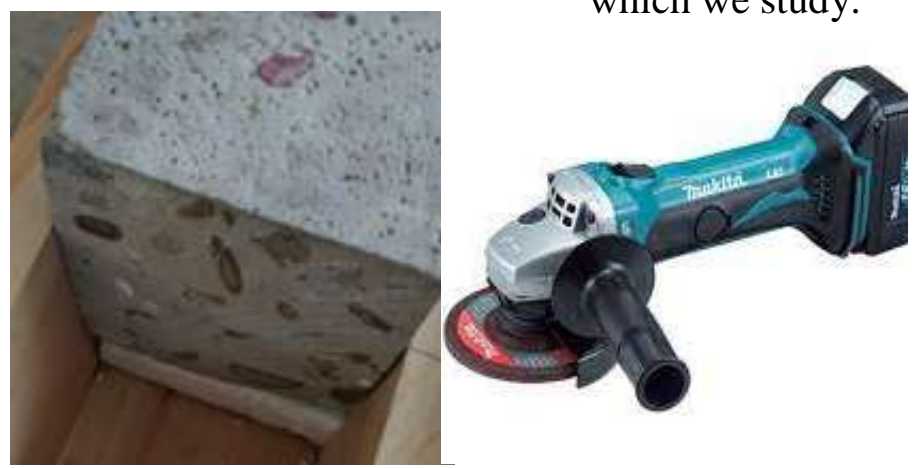

Fig. 1. Surface preparation by grinding 


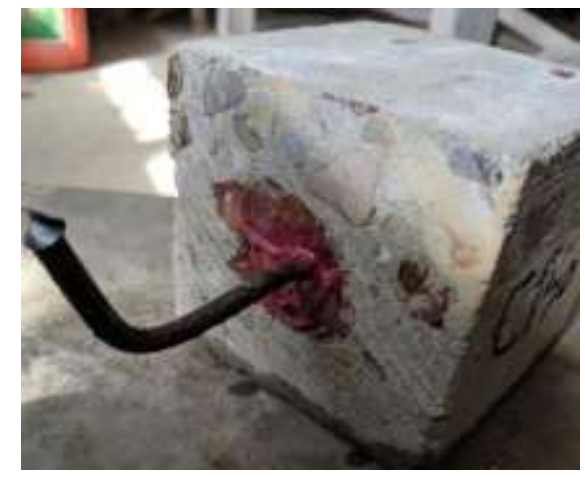

Fig. 2. Specimen with nails
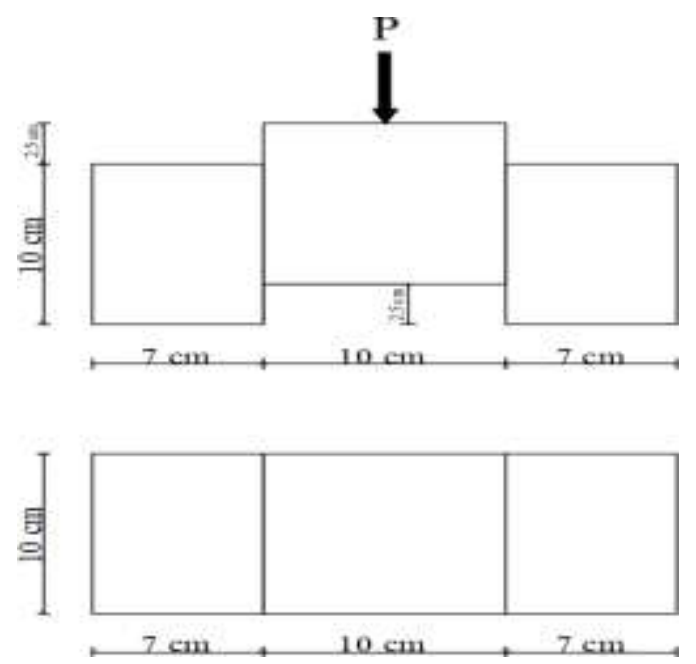

Fig. 4. Test sample dimensions

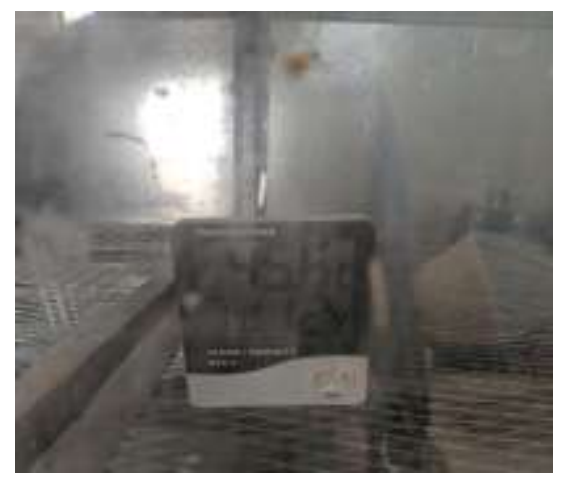

Fig. 6. Observing temperature and humidity in the oven
Vol.42, No.1. January2023

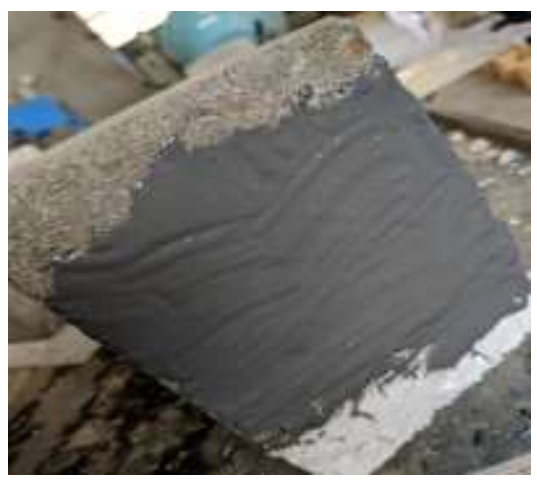

Fig. 3. Surface preparation with an epoxy

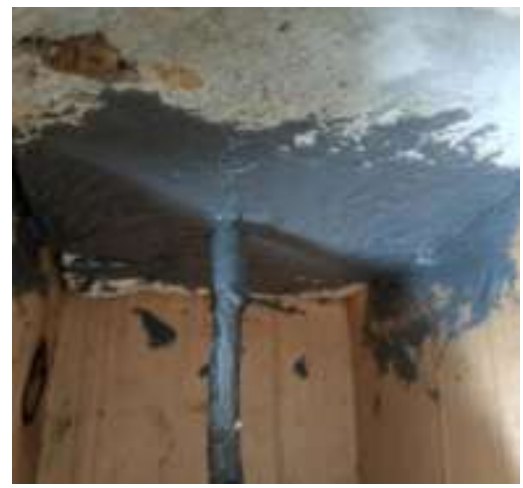

Fig. 5. Surface preparation with epoxy and nails

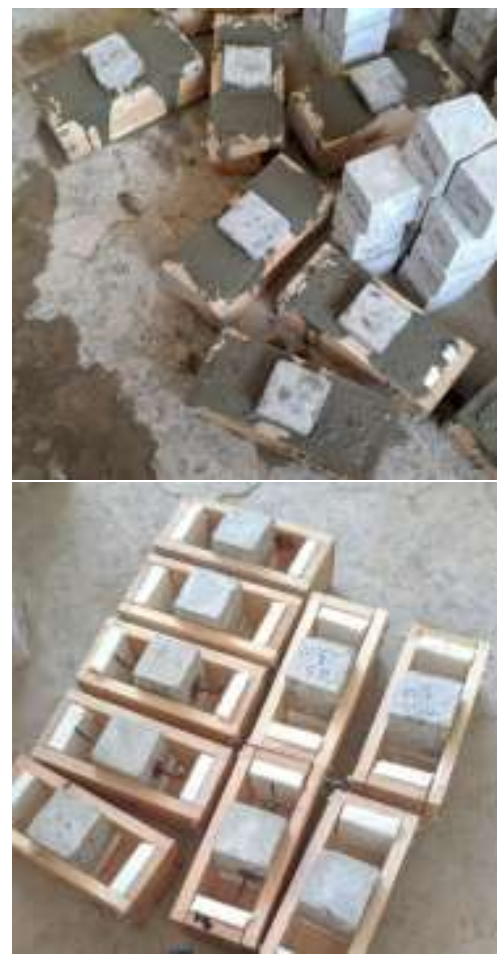

Fig. 7,8. During casting the samples 


\subsection{Test procedures}

We performed a total of 48 cubes $(10 * 10 * 10 \mathrm{~cm})$ represent the old concrete (of strength $15 \mathrm{MPa}$ ) and 12 sets for every new concrete (strength $15 \mathrm{MPa}$ ). We cast three samples of old concrete (denoted as CC15), three using epoxy (as C-CE15), three using nails only (as C-CN15), three using both nails' samples, and epoxy samples (denotes as C_CEN15). The sequences followed with the other strengths as shown in Table (3).

After taking out the specimens from the oven, we tested them (the substrate concrete eight weeks old and the new concrete jacket were four weeks old). With a compression machine test, a static loading occurs direct shear stress at the interface between old and new concrete. (Fig. 9) shows the test sample used for investigation for each case study; three specimens were loaded till failure and then get the average bond strength by MPa.

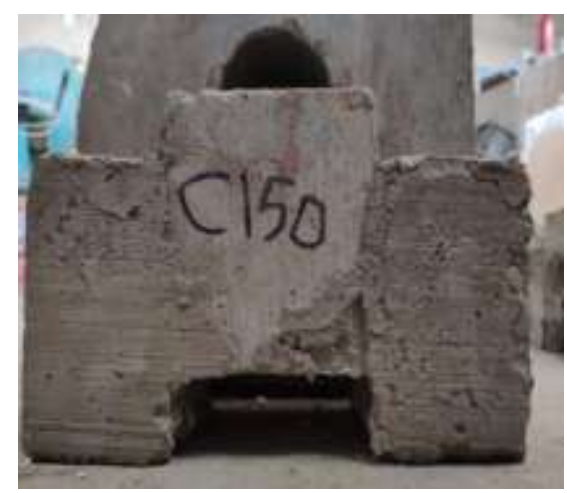

Fig. 9. Test sample

Table 3 variables abbreviations used in the test

\begin{tabular}{|c|c|c|c|c|}
\hline \multirow{2}{*}{$\begin{array}{c}\text { Cases of the } \\
\text { substrate surface } \\
\text { preparation }\end{array}$} & \multicolumn{4}{|c|}{ Grade of the new concrete overlay (MPa) } \\
\cline { 2 - 5 } & $\mathbf{1 5}$ & $\mathbf{3 0}$ & $\mathbf{4 0}$ & $\mathbf{5 0}$ \\
\hline Without using any & C-C15 & C-C30 & C-C40 & C-C50 \\
agent & C-CE15 & C-CE30 & C-CE40 & C-CE50 \\
\hline Using epoxy only & C-CN15 & C-CN30 & C-CN40 & C-CN50 \\
\hline Using nails only & C-CEN15 & C-CEN30 & C-CEN40 & C-CEN50 \\
\hline Using both of nails & Cond epoxy & C-CEN10 &
\end{tabular}




\section{Results and discussion:}

Table 4 shows the overall average shear stress at the interface between old and new concrete against each case of all cases in this test (16 cases). (Fig. 10) shows the shear failure at the interface between old and new concrete. We found no particle damage in the specimens cast without any bonding agents. Failed samples that had an epoxy agent the crack went throw the epoxy without any particles damage (Fig. 11). All of the specimens that had nails, show destruction with particles damage (Fig. 12). Table 4 shows increase of the interface bonding for Samples with a surface prepared by bonding agent or nails, and there is a slight increase in the bonding strength for each increase in the new overlay strength.

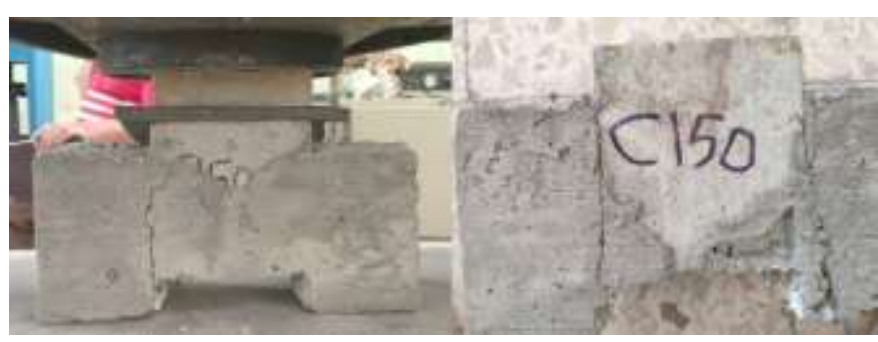

Fig. 10. Failure at the interface

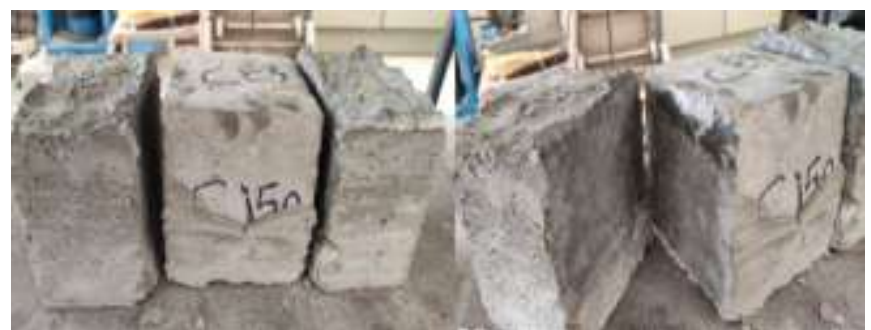

Fig. 11. De-bonding in case of epoxy resin

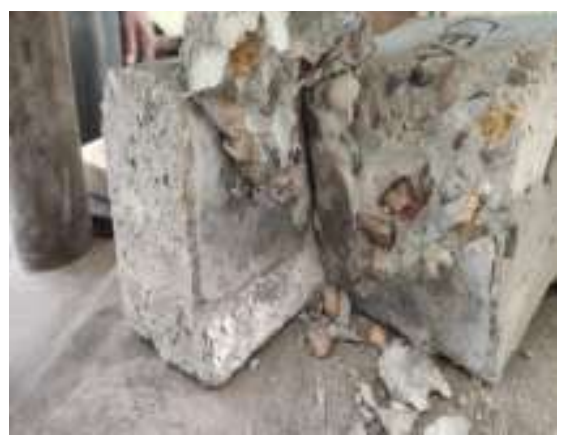

Fig. 12. Failure in case of nails

Table 4 Average Overall bond strength

\begin{tabular}{|c|c|c|c|c|}
\hline \multicolumn{5}{|c|}{ Average Overall bond strength (MPa) } \\
\hline \multirow{2}{*}{$\begin{array}{c}\text { cases of bond } \\
\text { between old and } \\
\text { new concrete }\end{array}$} & \multicolumn{3}{|c|}{ Grade of the new concrete jacket MPa } \\
\cline { 2 - 5 } & 15 & 30 & 40 & 50 \\
\hline C-C & 1.065 & 1.165 & 1.33 & 1.4 \\
\hline C-CE & 1.6 & 1.765 & 2.0 & 2.065 \\
\hline C-CN & 1.33 & 1.665 & 1.8 & 1.93 \\
\hline C-CEN & 2.0 & 1872.13 & 2.33 & 2.465 \\
\hline
\end{tabular}




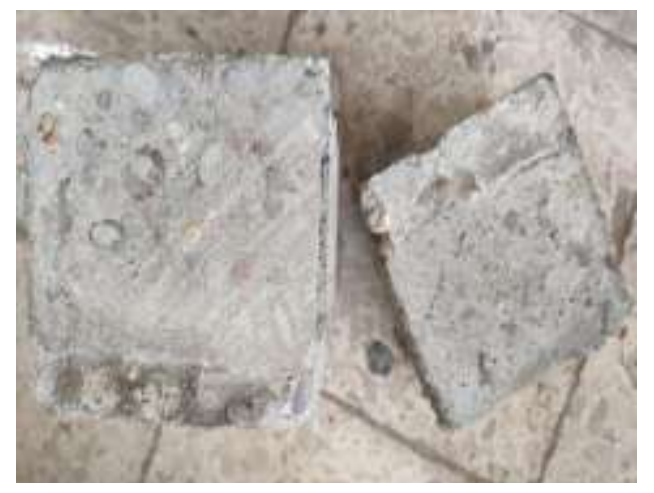

Fig. 13. Interface failure without using any bonding agents

Figure 14 shows Average Overall bond strength (MPa) for all cases and the correlations between them.

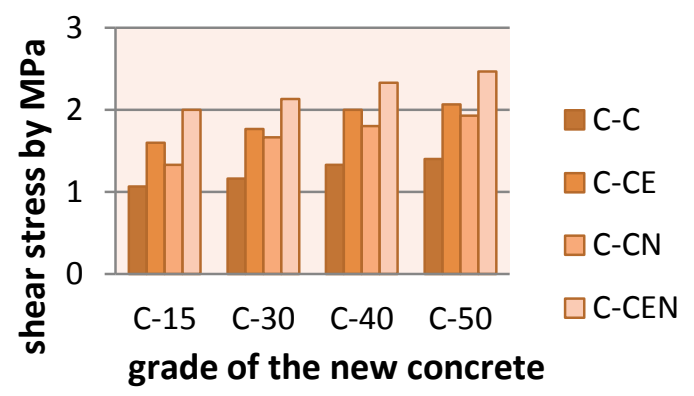

Fig. 14. Average bond strength for all cases

3.1. Effect of the new concrete strength only on the interfacial bond strength:

Figure 15 shows the effect of the new concrete grade on the bond between the new concrete and $15 \mathrm{MPa}$ old concrete strength.

The test specimens cast without any adhesive agent or shear connectors, by using

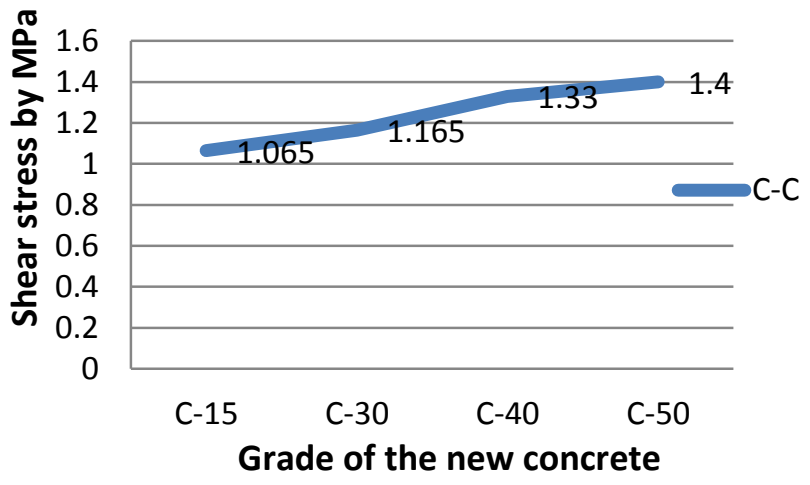

Fig. 15. Effect of the new concrete grade

a higher new concrete strength, the shear bond strength increased, and the increase of the interfacial shear strength was about $9 \%$, $24.9 \%, 31 \%$ when using a new concrete strength of 30, 40, $50 \mathrm{MPa}$ respectively. The highest rate of the bond strength at the interface noticed when using new concrete with a strength of $30 \mathrm{MPa}$, the rate of bond increases with the increase of the new concrete strength to be $30,40,50 \mathrm{MPa}$ is $0.67 \%, 1.65 \%, 0.7 \%$ respectively, which shows that the most effective strength of new concrete in the range between 30,40 MPa. By using new concrete strength (50 $\mathrm{MPa}$ ), the rate of bond strength decreases due to the brittle properties of the new concrete that leads to failure of the bond between new and old concrete.

An extremely high difference between the old concrete and the new one is not essential due to the increase in the bond strength. We 
can conclude that to achieve economic bond strength, the difference between new concrete strength and the old one should be 2-3 times the old concrete strength in case of no use of any adhesion agents.

\subsection{Effect of the new concrete strength} with using an adhesive agent on the interfacial bond strength:

Figure 16 shows the

effect of the new concrete grade when using an adhesive agent on the bond between the new concrete and $15 \mathrm{MPa}$ old concrete strength.

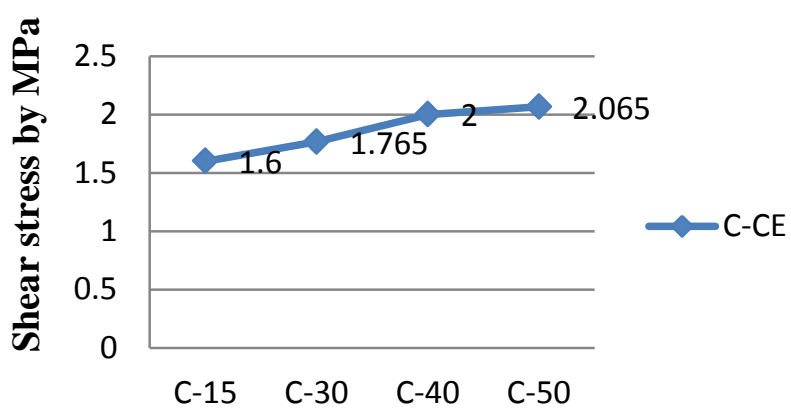

Grade of the new concrete

Fig. 16. Effect of the new concrete grade when using an adhesive agent

The test samples were cast with an adhesive agent (Master Brace $\mathrm{ADH}$ ) and without shear connectors. Using a higher concrete strength, the more bond strength we got, the increasing was $10.5 \%, 40 \%$,
$46 \%$ for using 30, 40, $50 \mathrm{MPa}$ new concrete strength respectively concerning $15 \mathrm{MPa}$ as a new concrete strength jacket. We noticed the highest rate of the bond strength between 30, $40 \mathrm{MPa}$ of the new concrete strength. Rates of increase of the bond strength were $1.1 \%, 2.35 \%, 0.65 \%$ for using $30,40,50$ $\mathrm{MPa}$ of the new concrete strength. The very high strength difference between the new and the old concrete not necessary to enhance the interfacial bond strength. So, we can conclude that to achieve an economic and a good bond strength when using an adhesive agent in hot, dry weather, we can use a new concrete bigger than 2-3 times than the old concrete strength.

\subsection{Effect of the new concrete strength when using shear connectors on the interfacial bond strength:}

Figure 17 shows the effect of the new concrete grade when using shear connectors on the bond between the new concrete and $15 \mathrm{MPa}$ old concrete strength.

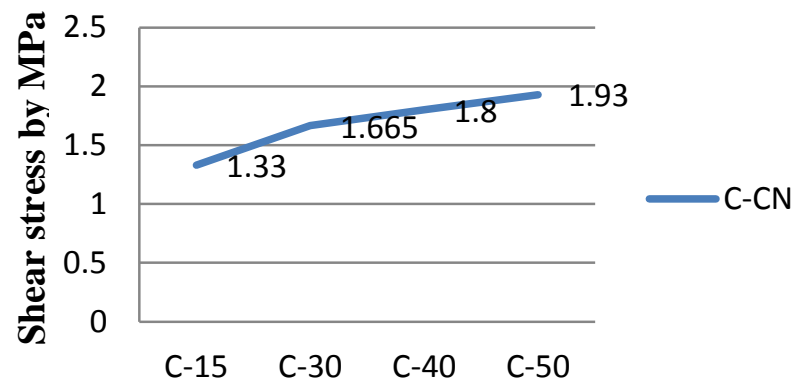

Grade of the new concrete

Fig. 17. Effect of the new concrete grade when using shear connectors 
The test specimens were cast with shear connectors (one for each side) and without any adhesive agent. Using nails shows more bond strength at the interface when using a higher new concrete strength.

The increase in the bond strength was $25 \%$, $35 \%, 60 \%$ for using a new concrete of 30 , 40, and $50 \mathrm{MPa}$, respectively. Concerning the reference sample with a new jacket of concrete strength of $15 \mathrm{MPa}$, the rates of increment of bond strength were $2.25 \%$, $1.35 \%, 1.3 \%$ by using new concrete of 30 , 40, and $50 \mathrm{MPa}$ strength, respectively.

We found the high bond strength set between 15 and $30 \mathrm{MPa}$ however, the maximum increase at $50 \mathrm{MPa}$. So, if we look from an economic point of view, we can use a new concrete strength two times bigger than that of the old one at hot, dry weather curing because it gives the maximum rate of increasing the bond strength and better bonding strength with $25 \%$ more than the reference one.

Using very high concrete strength like $50 \mathrm{MPa}$ shows better $(60 \%)$ bonding strength because of high bonding between the steel bars with the new concrete. The high density of the new concrete used in this strength is not economical and gave a minimal increase in the bond strength concerning the used concretes in this investigation.

\subsection{Effect of the new concrete strength when using shear connectors and an adhesive agent on the interfacial bond strength:}

Figure 18 shows the effect of the new concrete grade when using shear connectors and an adhesive agent on the bond between the new concrete and $15 \mathrm{MPa}$ old concrete strength.

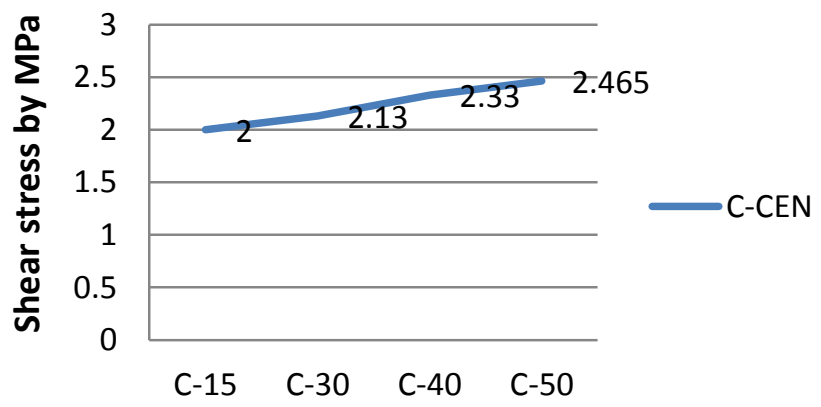

Grade of the new concrete

Fig. 18. Effect of the new concrete grade when using shear connectors and an adhesive agent

We cast test samples after preparing the interface surfaces with an adhesive agent (Master Brace ADH) and one shear connector for each side. Using new different concrete strengths $30,40, \quad 50 \quad \mathrm{MPa}$ concerning the reference sample, $15 \mathrm{MPa}$ give an increment of $6.5 \%, 16.5 \%, 23.25 \%$ in bonding strength at the interface, rates of increase in bond strength for different concrete strengths were $0.9 \%, 2 \%, 1.35 \%$ for 30, 40, $50 \mathrm{MPa}$ new concrete strength. 
The adhesive agent has additional control on the bonding strength, in this case, because we observed that the maximum rate was between 30, $40 \mathrm{MPa}$ for the new concrete overlay. The same result we got from the case of the adhesive agent only.

The conclusion that; we can use great strength 2-3 times for the overlay than the old one to get the best rate and bonding strength at the interface from an economic point of view in hot, dry weather.

3.5 Effect of using bonding agents on the bond strength at the interface in case of using the same old concrete grade in the new jacket:

Figure 19 shows the effect of using bonding agents like nails and an adhesive agent on the bond power when using the strength of the old concrete in the overlay casting.

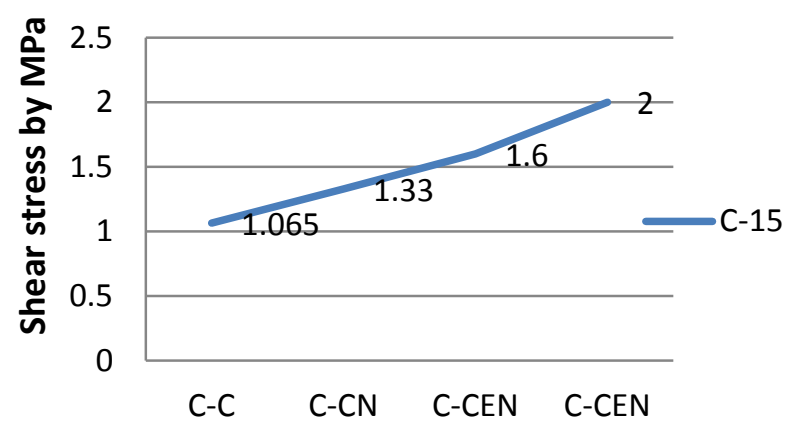

Surface preparation cases

Fig. 19. New overlay with $15 \mathrm{MPa}$

Test specimens were cast with a new concrete with a grade of $15 \mathrm{MPa}$ with different surface preparation cases, without any bonding agents, using nails, using an adhesive agent, and using nails and an adhesive agent. Using shear connectors and an adhesive agent with both of them enhanced the interfacial bond with $25 \%$, $53.5 \%, 93.5 \%$, respectively. Concerning the reference sample (without any bonding agents), we observed that using an adhesive agent gives more bonding strength than nails with a $20 \%$ increase of bond strength.

Using both of them gives an increment of $25 \%$ than the bond strength in using an adhesive agent only. So, we can conclude that using shear connectors and an adhesive agent gives the highest interfacial bond strength in using the same old concrete strength in the overlay in hot, dry weather.

\subsection{Effect of using bonding agents on the bond strength at the interface in case of using 30 MPa strength in the new jacket:}

Figure 20 shows the effect of using bonding agents like nails and an adhesive agent on the bond strength when using 30 $\mathrm{MPa}$ concrete strength in casting the overlay.

We cast test specimens with a new concrete jacket of $30 \mathrm{MPa}$ strength with different surface preparation cases. The results showed that using nails, an adhesive 


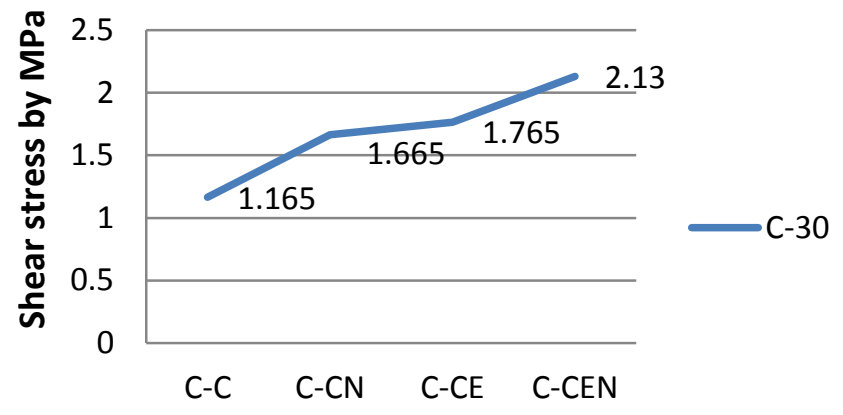

Surface preparation cases

Fig. 20. New overlay with $30 \mathrm{MPa}$

agent, and both of them increased interfacial bond strength by $50 \%, 60 \%$, and $96.5 \%$, respectively. Regarding the reference sample (cast without any bonding agents), we noticed that using an adhesive agent enhances the bond strength by $6 \%$ than th bond strength when using shea. connectors. Shear connectors with good new concrete strength gave the same bond strength when using an adhesive agent, which can be explained by, the quality, proper density, and flexural properties of the new concrete. When we increase its strength, using both shear connectors and an adhesive agent, the bond strength increased by $21 \%$ more than using an adhesive agent only. So, we can use both bonding agents to get the maximum bond strength at the interface in case of using it two times the old concrete strength in hot, dry weather.

\subsection{Effect of using bonding agents on the bond strength at the interface in case of using 40 MPa strength in the new jacket:}

Figure 21 shows the effect of using bonding agents like nails and an adhesive agent on the bond strength when using 40 $\mathrm{MPa}$ concrete strength in casting the overlay.

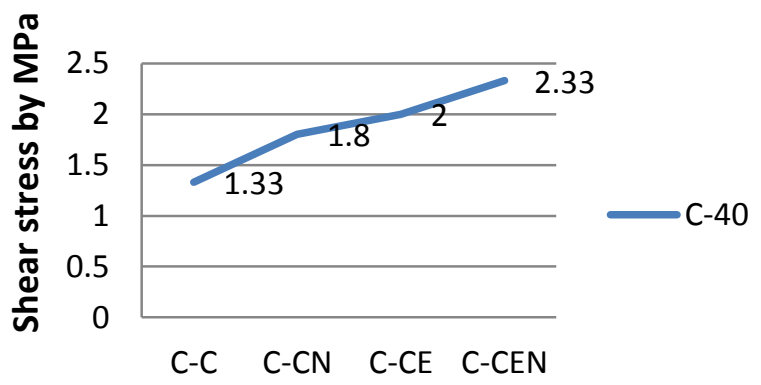

Surface preparation cases

Fig. 21. New overlay with $40 \mathrm{MPa}$

We cast the new concrete samples using $40 \mathrm{MPa}$ concrete strength containing silica fume to get high strength with more density concrete, with different surface preparation cases. The results showed that using nails, adhesive agents, and both together gave more bond strength by $35 \%$, $50 \%$, and $75 \%$, respectively than reference samples (cast without any bonding agents). Using an adhesive agent causes an increment by $11 \%$ in bond strength than using nails only, and both gave an increment by $16.5 \%$ than using an adhesive agent only. The increase in bond strength in this state is not high like the previous states is due to the overlay strength that provides a 
perfect interfacial bond for the reference sample (cast without any bonding agents), compared with the state $(15,30 \mathrm{MPa})$ of concrete strengths. The increment of bond strength, as we mentioned before, shows that using both shear connectors and an adhesive agent gives the highest bond strength in the case of casting a new concrete with about 2.5 times than the old concrete strength in hot, dry weather.

\subsection{Effect of using bonding agents on the bond strength at the interface in case of using 40 MPa strength in the new jacket:}

Figure 22 shows the effect of using bonding agents like nails and an adhesive agent on the bond strength when using 40 MPa concrete strength in casting the overlay. We cast test specimens with a new concrete strength of $50 \mathrm{MPa}$ with different surface preparation cases. The increase of bond strength was $38 \%, 47.5 \%$, and $76 \%$ using nails, an adhesive agent, and both of them respectively for the reference sample. This state is like the last one (using $40 \mathrm{MPa}$ ) because both represent a high strength concrete state and each of them contains silica fume so, the properties are mostly the same. We can notice that the increment of bond strength was $7 \%$ when using an adhesive agent than using nails only and was $19 \%$ when using both of them than using an adhesive agent only and the results are close to the results of the last state. So, we recommend that using both bonding agents in case of using a new concrete with a strength higher than 3.5 times than the old concrete in hot, dry weather to get the maximum bond strength.

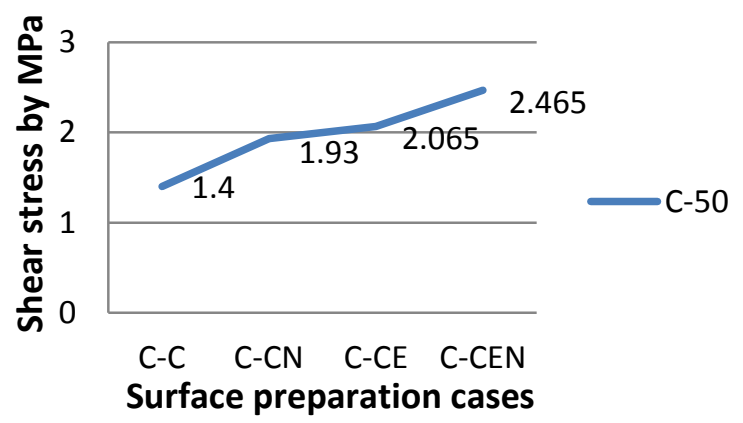

Fig. 22. New overlay with $50 \mathrm{MPa}$

\subsection{Relative interfacial bond strength using different techniques:}

Table 5 shows the relative bond strength at the interface with respect to the original case (casting the same grade for the old concrete as a new one without using any bonding agents). The results show that using high concrete strength $50 \mathrm{MPa}$ with an adhesive agent and shear connectors gives maximum bond strength with a relative percentage of $231 \%$ from the original case, for the same surface preparations using a new concrete with a strength $40 \mathrm{MPa}$ gives $219 \%$ relative bond strength and using a 
new concrete with $30 \mathrm{MPa}$ strength gives $200 \%$ relative bond strength from the original case, so it is obvious that surface preparations using bonding agents have a greater impaction on the bond strength than using a higher concrete strength and it has a lower cost than using a very high concrete strength. From results using a new concrete has a double value than the old one with using bonding agents is the best way to have good and economic bond strength.

Table 5 Relative bond strength

\begin{tabular}{|c|c|c|c|}
\hline $\begin{array}{c}\text { Used } \\
\text { techniques }\end{array}$ & $\begin{array}{c}\text { Relative bond } \\
\text { strength \% }\end{array}$ & $\begin{array}{c}\text { Used } \\
\text { techniques }\end{array}$ & $\begin{array}{c}\text { Relative bond } \\
\text { strength \% }\end{array}$ \\
\hline C-C15 & 100 & C-C40 & 125 \\
\hline C-CE15 & 150 & C-CE40 & 188 \\
\hline C-CN15 & 125 & C-CN40 & 169 \\
\hline C-CEN15 & 188 & C-CEN40 & 219 \\
\hline C-C30 & 110 & C-C50 & 131 \\
\hline C-CE30 & 166 & C-CE50 & 194 \\
\hline C-CN30 & 156 & C-CN50 & 181 \\
\hline C-CEN30 & 200 & C-CEN50 & 231 \\
\hline
\end{tabular}


Vol.42, No.1. January 2023

\section{REFERENCES}

(1) Abd Malek, Nur Adibah Ayuni, Khairunnisa Muhamad, Mohd Zulham Affandi Mohd Zahid, Nur Ain Hamiruddin, Norrazman Zaiha Zainol, Norhaizura Yahya, Nurulashikin Bahaman, and Nurfaraheen Mohd Ramli. 2018. "Evaluation of bond strength between normal concrete and high performance fiber reinforced concrete (HPFRC)." In MATEC Web of Conferences, 01015. EDP Sciences.

(2) Al-Fasih, M Yahya, ME Mohamad, IS Ibrahim, Y Ahmad, MA Mohd Ariffin, NN Sarbini, RN Mohamed, and ABH Kueh. 2021. 'Experimental and numerical evaluations of composite concrete-to-concrete interfacial shear strength under horizontal and normal stresses', Plos one, 16: e0252050.

(3) AL Hallaq, Ahmed, Bassam A Tayeh, and Samir Shihada. 2017. 'Investigation of the bond strength between existing concrete substrate and UHPC as a repair material', Investigation of the Bond Strength Between Existing Concrete Substrate and UHPC as a Repair Material, 6.

(4) Elbakry, Hazem M. F., and Ahmed M. Tarabia. 2016. 'Factors affecting bond strength of RC column jackets', Alexandria Engineering Journal, 55: 57-67.

(5) Haber, Zachary B, Jose F Munoz, Igor De la Varga, and Benjamin A Graybeal. 2018. 'Bond characterization of UHPC overlays for concrete bridge decks: Laboratory and field testing', Construction and Building Materials, 190: 105668.

(6) Li, Bo, and Eddie Siu Shu Lam. 2018. 'Influence of interfacial characteristics on the shear bond behaviour between concrete and ferrocement', Construction and Building Materials, 176: 462-69.

(7) López-Carreño, Rubén-Daniel, Pablo Pujadas, Sergio HP Cavalaro, and Antonio Aguado. 2017. 'Bond strength of whitetoppings and bonded overlays constructed with selfcompacting high-performance concrete', Construction and Building Materials, 153: 835-
45.

(8) Naresh, J, B Lavanya, and K Suresh Kumar. 2021. "A Study on bond strength of normal concrete to high volume fly ash concrete." In IOP Conference Series: Materials Science and Engineering, 012082. IOP Publishing.

(9) Nguyen, Quy, C. Serhatoğlu, and Ramazan LIVaoĞLu. 2018. The Effect of Shear Connector Ratios on the Concrete-to-Concrete Interface.

(10) Ramasamy, Krishnaraja Ammapalayam, Yuvarani Sadasivam, Vishnu Rajaram, Yogesh Nithiyananthan, S Anandaraj, and M Harihanandh. 2021. "Review on Bond Strength of Recycled Aggregates in Concrete." In IOP Conference Series: Materials Science and Engineering, 012108. IOP Publishing.

(11) Rith, Makara, Young Kyu Kim, Seung Woo Lee, Jun Young Park, and Seung Hwan Han. 2016. 'Analysis of in situ bond strength of bonded concrete overlay', Construction and Building Materials, 111: 111-18. 